Health \& Medicine | Lynn Woods

\section{Managing behavioural symptoms of dementia in Latinos}

\begin{tabular}{|c|c|c|}
\hline $\begin{array}{l}\text { Dr Diana Lynn Woods, } \\
\text { Azusa Pacific University, has } \\
\text { dedicated her research to } \\
\text { the greater understanding of } \\
\text { dementia and the methods } \\
\text { used to treat behavioural } \\
\text { symptoms of dementia. Her } \\
\text { recent work has focused } \\
\text { on Latinos with dementia } \\
\text { who exhibit behavioural } \\
\text { symptoms of dementia and } \\
\text { ways to incorporate genetic } \\
\text { and cultural factors into } \\
\text { intervention strategies. }\end{array}$ & 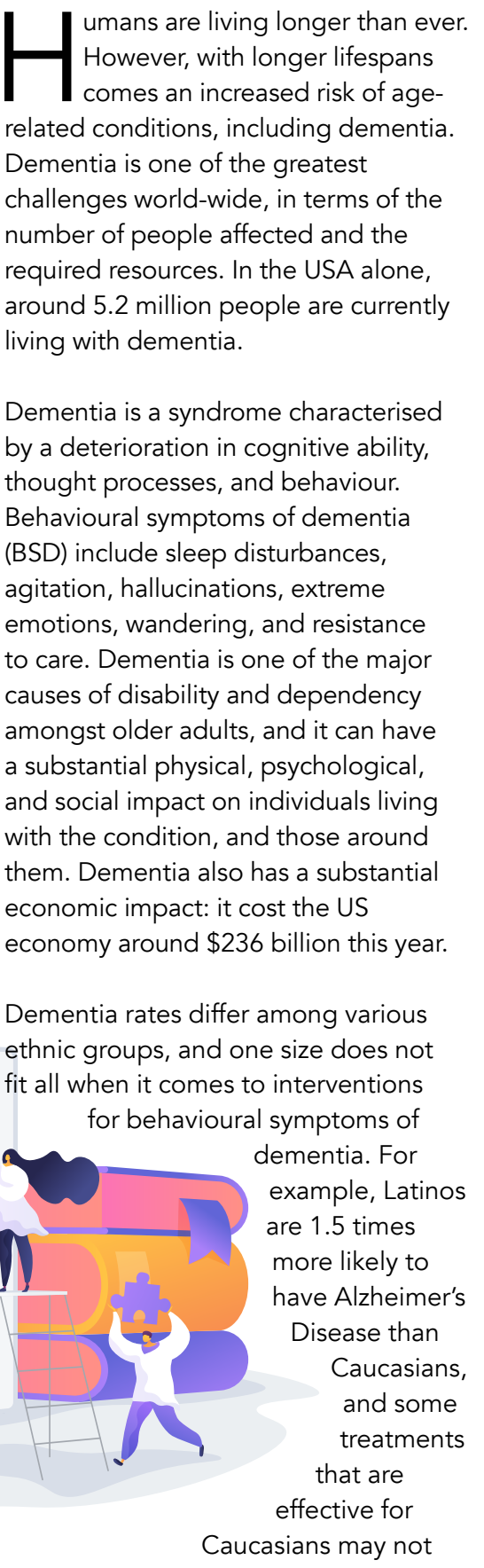 & $\begin{array}{l}\text { be effective for Latinos. However, } \\
\text { the best way to treat the behavioural } \\
\text { symptoms of dementia in ethnic } \\
\text { and racial minority groups is not yet } \\
\text { fully understood. } \\
\text { To address this, Dr Diana Lynn } \\
\text { Woods from Azusa Pacific University } \\
\text { researches ways to deliver culturally } \\
\text { appropriate treatments to older Latinos } \\
\text { with dementia. Dr Woods' research } \\
\text { explores the current ways that BSDs } \\
\text { are assessed and treated in Latino } \\
\text { populations, in addition to the role of } \\
\text { genetic and environmental factors in } \\
\text { prescribing medications to Latinos with } \\
\text { BSD. A further aspect of Dr Woods' } \\
\text { work investigates the effectiveness of } \\
\text { non-pharmacological approaches for } \\
\text { BSD, which include the integration of } \\
\text { ethnocultural and traditional healing } \\
\text { systems into existing Western non- } \\
\text { pharmacological approaches. } \\
\text { CULTURAL FACTORS OF } \\
\text { BEHAVIOURAL SYMPTOMS OF } \\
\text { DEMENTIA } \\
\text { Ethnic minorities are often } \\
\text { underrepresented in dementia research, } \\
\text { and so our understanding about } \\
\text { ethnic differences in the symptoms } \\
\text { and treatments of dementia remains } \\
\text { limited. Future dementia research must } \\
\text { include ethnic minority individuals so } \\
\text { help us understand the similarities and } \\
\text { differences in BSD across different } \\
\text { ethnic groups. } \\
\text { Compared to White populations, } \\
\text { Hispanic individidals often receive } \\
\text { a diagnosis at a much later stage } \\
\text { of dementia and thus may have an } \\
\text { increased risk of exhibiting behavioural } \\
\text { symptoms of dementia. Cultural factors }\end{array}$ \\
\hline
\end{tabular}

can influence the interpretation and recognition of behavioural symptoms younger people are expected to show high levels of respect for their elders. the acknowledgement of changes in cognition and/or behaviour is often delayed. Indeed, Dr Woods' notes previous research that showed $65 \%$ of Hispanic caregivers dismissed symptoms of dementia due to the bel that it is a normal part of ageing.

Moreover, on relocating to the United States, many minority ethnic groups choose to retain their traditional healing practices. Traditional heal approaches to dementia often incorporate spiritual beliefs, such as the illness being caused by being bewitched, and focus on restoring balance in the spirtual realm. Caregiser help from traditional helers alongside clinical healthcare professionals. Therefore, to effectively manage BSD in Latino populations, it is critical for healthcare providers to enquire and become knowledgeable about the traditional healing methods of Latino groups. Interestingly, positive outcomes have been shown when healthcare providers use an inclusive approach to healing in clinical settings.

\section{PHARMACOLOGICAL} INTERVENTIONS

A range of pharmacological and A non-phamacological interventions are available to treat BSD. However symptoms and behavioural chang is vital before BSD symptoms are tre is

In terms of pharmacological interventions, the class of medications used for treating BSD is psychotropic medications, which includes antipsychotics, antidepressants, and sedative hypnotics. Dr Woods argues that pharmacological interventions are often over-used, or used inappropriately, and can therefore be ineffective for people with BSD. Some evidence even suggests that psychotropic medications can have a detrimental effect on individuals. Of those taking psychotropic medications, $30 \%$ are ass
of mortality.

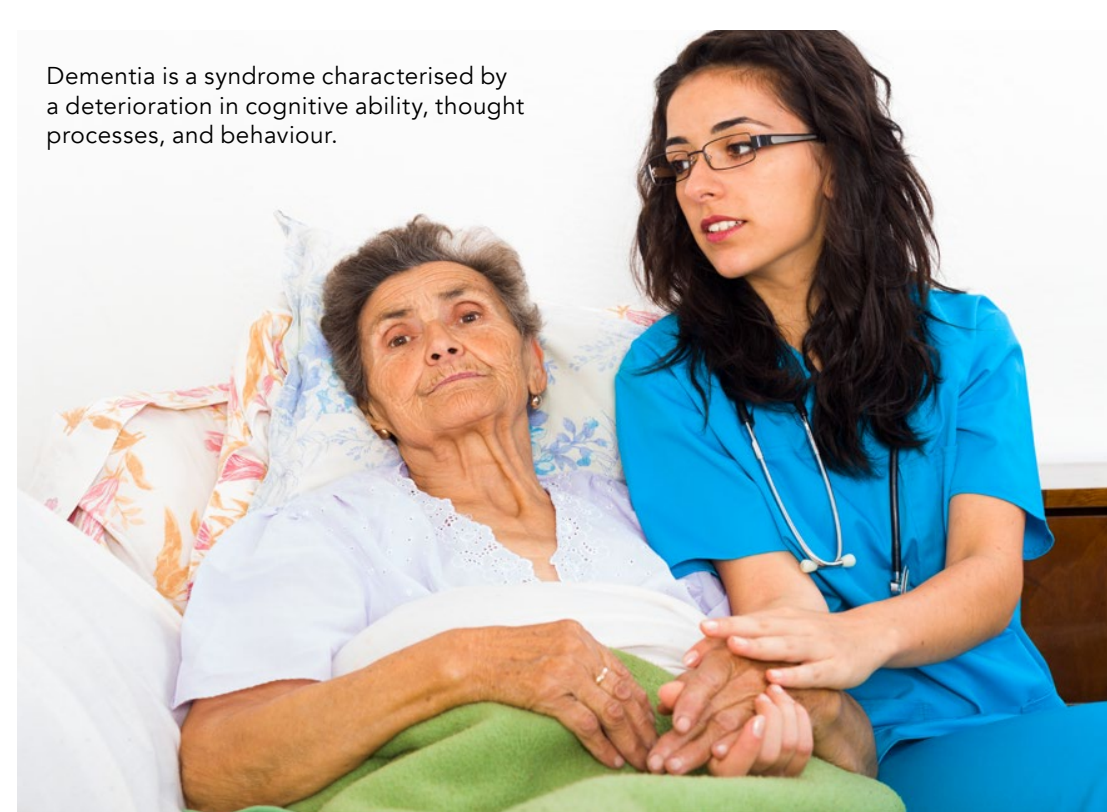

In the USA alone, around 5.2 million people are currently living with dementia.

Indeed, there tends to be an assumption excreted, plus their mechanisms of of universality in prescribing practices of action. It is essential that the genetic medication for BSD, largely influenced by the dominant Caucasian population in whom the drugs were tested.

Cultural or ethnic factors may influence an individual's response to medication and indeed evidence shows significant differences in response to psychotropic drugs in different ethnic groups This field of research, known as 'ethnopharmacology,' explores the ways in which genetic differences between ethnic populations can influence the
ways in which drugs are absorbed and variation of these enzymes be pharmacological treatments since they have a significant effect on the timing of medications and the dosage for optima therapeutic effect.

THE USE OF PSYCHOTROPICS AND ROLE OF GENETIC VARIATION Psychotropic drugs, while commonly used to manage behavioural disturbances in people with dementia, are not recommended as the firstine of

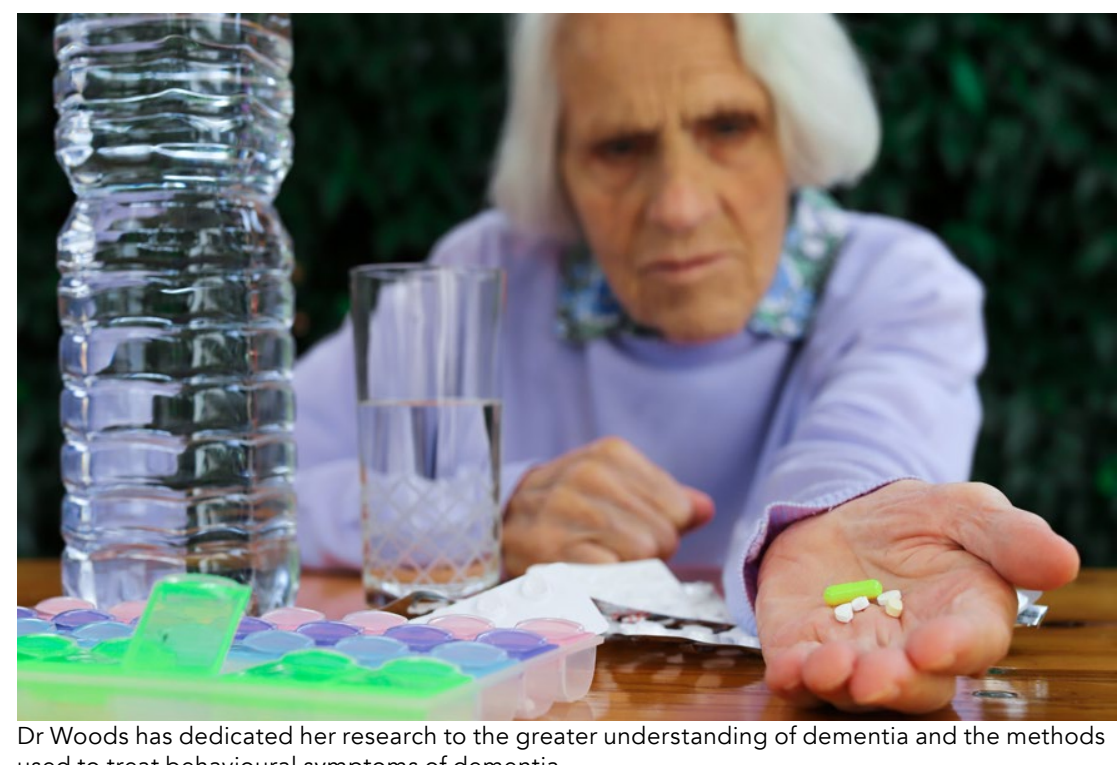




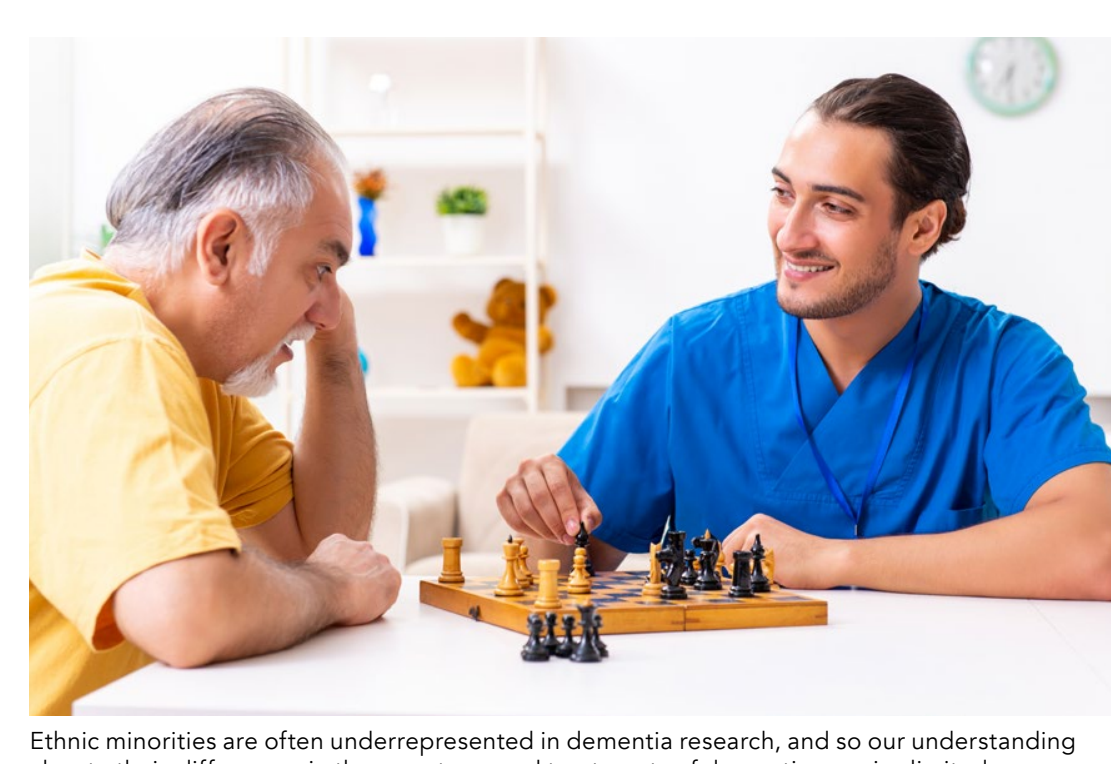

Ethnic minorities are often underrepresented in dementia research, and so our understanding
about ethnic differences in the symptoms and treatments of dementia remains limited.

effects. The outcomes of psychotropic medications are often less effective than hoped for. Several factors can impact upon the efficacy of these medications, age, and ethnicity. For example, there is a lack of evidence to suggest that psychotropic drugs are effective in older Latino adults. Genetic differences also play a significant role in the effectiveness tobacco smoking, which is common profound influces, can have a several psychotropic drugs. Much more work is needed to fully understand geneenvironment interactions in Latinos, particularly regarding psychotropic medications. psychotropic medications, the Beers

Much more work needs to be done to fully understand gene-environment interactions in Latinos, particularly with regards to psychotropic medications.

and the same drug can be metabolised ferently, depending on the individual s genetic profle. DrW if genetic factors are considered when prescribing medications.

\section{EPIGENETIC FACTORS}

o complicate matters further,

teractions among genes, environment,

and culture also can influence an

individual's response to psychotropic

medication. Environmental factors

metabolism, distibe in the absorption,

of psychotropic metion, and eliming

environmental factors molify te way

which genes are expressed i.e., they

Criteria for Potentially Inappropriate Medication Use in Older Adults

recommends that psychotropics should and should only be prescribed if nonpharmacological interventions have be unsuccessful. Dr Woods recommends further research is needed to examine responses to psychotropic medication across different ethnic groups. She also proposes that healthcare professionals be informed about the risks of prescribing psychotropics to individuals of different ethnic groups and informed about the various non-pharmacologica approaches to treating dementio.

NON-PHARMACOLOGICAL

Non-pharmacological interventions are

recommended as first line treatments for dementia care. Non-pharmacologica include cognitive/ementia can interventions (e.g, reminiscence therapy), sensory stimulation (e. aromatherapy; massage/touch therapy) and other psychosocial interventions (e.g., animal assisted therapy). Those with a sensory focus show more promise than others.

There have been several advances in research into non-pharmacological interventions, although there is currently no consensus about how to categorise these interventions or make evidencebased recommendations for their use. There have been several hundred small clinical trials which have shown promising results to suggest that have potential benefits for individuals with dementio and their caregivers. However, many of these studies have methodological issues which hamper our understanding of the effectiveness of non-pharmacological interventions. Future research using large-scale clinical trials is therefore needed to better understand the effectiveness of non-pharmacological interventions in dementia. Individuals from different ethnic groups must be included in future research, to understand whether there is variation in responses to specific non-

Dr Woods' research suggests that an interdisciplinary team approach has the variety of knowlectese areas and offering

\section{CONCLUSION}

oods' research highlights the need for additional interdisciplinary research into BSD, specifically within the Latino population. She asserts the importance of healthcare providers acquiring knowledge about traditional healing practices that many Hispanic/Latinos use and working with healers to achieve positive treatment ints that psychotropic medications are used with extreme caution due to the many negalive side effects. As for nonpharmacological interventions, turther research is needed so that curent

\subsection{Behind the Research}

\section{Dr Lynn Woods}

E: dwoods@apu.edu T: $+1626815-6310$ - office W: https://www.apu.edu/nursing/faculty/dwoods/

\section{Research Objectives}

Dr Diana Lynn Woods' research focuses on genetic variations, ethnopharmacology, and the biologica (a)

\section{Detail}

Lynn Woods

Department of Doctoral Programs

University

Office: 606 Huntington Drive, Room 221 Monrovia, CA 91016

Bio

Dr Diana Lynn Woods PhD, RN, APRN-BC, FGSA, FAAN is an educator, nurse practitioner and researcher. Her work aims to develop and disseminate knowledge for the humanistic care of persons with dementia. For 25 years, her work has focused on those with Alzheimer's (BSD), whe exh hibution of genal symptoms of dementia BSD), the contribution of genetics and stress, and onpharmacological treatments.

\section{Collaborators}

DrLinda Phillips

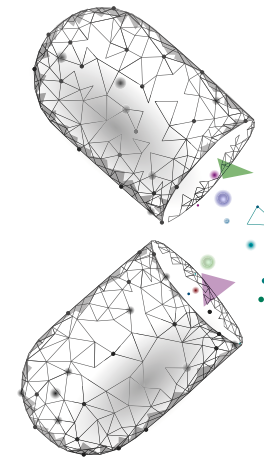

AZUSA PACIFIC

\section{References}

Woods, D.L. (2020). Behavioral Symptoms of Dementia in Latinos. Pharmacological, Non- pharmacological, and Ethnocultural Healthcare Interventions. In H. Y. Adames, Y. N. Tazeau (eds.), Caring for Latinxs with Dementia Y. N a Globalized World (pp. 187-203). https://do org/10.1007/978-1-0716-0132-7_11

Galik, E. (2016). Treatment of dementia: Nonpharmacological approaches. In M. Boltz and J.E. Galvin (Eds.) Dementia care: An evidence approach (pp. 97-112). ger McRae, J. (1987) Therapeutic Touch: A Practical Guide . Alfred A. Knopf Inc: New York

Gerdner, L.A. (2015). Ethnicity is an inherent criterion for assessment of individualized music for persons with

\section{Personal Response}

How can we ensure that Latino populations are

II Ensuring may not be possible. Holding health fairs at churches and local community areas, indicating research stude for that can inpo adelts to be pat of is a good start.

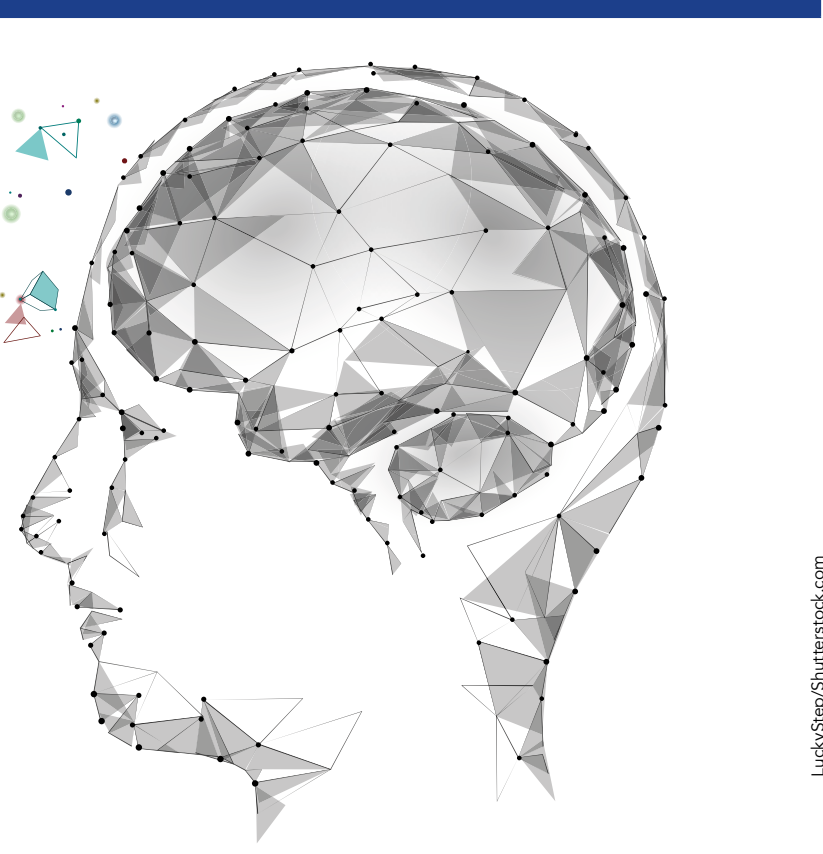

